\title{
Librarianship as Intellectual Craft: The Ethics of Classification in the Realms of Leisure and Waged Labor
}

\author{
Jonathan Cope \\ College of Staten Island, City University of New York, 2800 Victory Boulevard, \\ Staten Island,, NY 10314, <jonathan.cope@csi.cuny.edu>
}

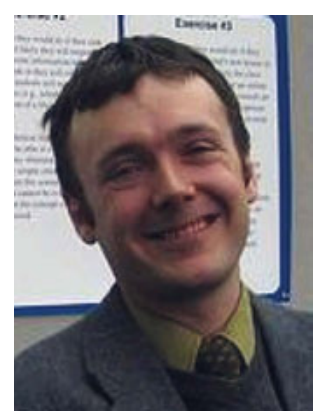

Jonathan Cope is a Reference/Instruction Librarian at the College of Staten Island (CSI), CUNY. Since coming to CSI in 2007, he has contributed to the library instruction program and provided reference services. Since 2008, he has been the coordinator of virtual reference services. Cope holds master's degrees in both library science and liberal studies. Recently, he has contributed a chapter to the edited collection Critical Library Instruction: Theories and Methods (Library Juice Press, 2010), which discusses the applicability of social power research to information literacy. Cope's current research is focused on the ways in which library and information literacy work is situated within specific social, cultural, economic, and disciplinary contexts.

Cope, Jonathan. Librarianship as Intellectual Craft: The Ethics of Classification in the Realms of Leisure and Waged Labor. Knowledge Organization. 39(5), 356-362. 14 references.

ABSTRACT: This paper develops an ethical conception of library labor as an intellectual craft that can serve as an alternative to a deterministic discourse of technological transformation. In this paper, the author proposes a model of librarianship as an intellectual craft that can be used as an "ideal type" in comparison to recent transformations in the practice of librarianship. This paper then examines the rise of participatory classification in the realm of leisure in user-generated classification schemes (e.g., folksonomies) as a way of examining some of the difficult ethical questions that this ideal of intellectual craft poses when applied to contemporary conditions. Marx's concept of surplus value is used to examine how donated labor adds to the general knowledge. This paper concludes by advocating for the general expansion of leisure coupled with the promotion public institutions that support the craft of those who organize information in a broadly defined public interest. In an era of dramatic change, such a framework offers a positive ethical account of librarians and information professionals' labor that is not wholly dependent on a discourse of market exchange.

Received 9 July 2012; Accepted 9 July 2012

\subsection{Introduction}

To state that a "discourse of technological transformation" has had a profound impact on the ways in which western capitalist liberal democratic societies conceptualize workplace activity seems to be so obvious that it is hardly worth noting. From the pages of Wired Magazine to bestselling odes about the impact of the information economy, the narrative of teleological technological transformation has solidified into a consistent popular culture trope: technology and market forces are constantly revolutionizing the way human societies exist, and, in order to labor in these societies, social actors must adapt to these changes, not just to prosper, but in order to simply survive. The recession that began in 2008 has only amplified this pervasive sense of precarity. When this kind of narrative becomes uncoupled from one that examines the social, economic, and political institutions and the power relationships within a particular society, social actors have diminished agency to affect the ways in which technological change is implemented. For those who labor in professions that are directly involved in the production and dissemination of new commodities, this can provide them with new markets for their labor. However, what do these 
transformations entail for those directly involved in the organization of information in a broadly defined public interest?

Given that a key historic mission of U.S. library systems has been to organize and make information accessible to a multitudinous public for the purposes of the "common good" in a democratic society, this narrative can act to limit the discursive terrain upon which the role of the library and classification is defined. Libraries came into existence in large part due to the advent of particular technologies, such as mass printing, during the 19th century. Therefore, technological transformation is nothing new to information classifiers. Although a great deal has been written within the profession about the relevance of libraries in an era of rapidly changing technologies, little attention has been paid to the philosophical foundations of the day-to-day practice of librarianship and its relationship to this discourse of technological transformation. In this essay, I argue that the concept of intellectual craft provides librarians with a normative intellectual ideal that may be used to evaluate and shape day-to-day practice in the face of technological and economic transformation. I then examine the rise of participatory classification in the realm of leisure in user-generated classification schemes (e.g., folksonomies) as a way of examining some of the difficult ethical questions that this ideal of intellectual craft poses when applied to contemporary conditions. I conclude by advocating for the general expansion of leisure coupled with an advocacy for public institutions that support the craft of those who organize information in a broadly defined public interest.

\subsection{Librarianship as intellectual craft}

For the purposes of the present inquiry, an idealized conception of librarianship and a classifier's work activity as an intellectual craft is proposed. This conception involves the relationship of individual librarians to their understanding of the whole of their particular institutions, the broader world of information, and the relationships of the social actors who use knowledge and information. The relation of librarianship and classification to this practice suggests an endeavor with both theoretical and practical dimensions. What follows is simply meant to sketch an outline of normative concepts that might constitute a Weberian "ideal type" of librarianship as an intellectual craft. As with any intellectual exercise, the intention is the development of a set of analytical tools to examine social reality. Of course, the characteristics of this ideal can be contested and scrutinized as so much abstract conjecture. However, without articulating an idealized conception of librarianship and classification, the practicing craftperson finds that he or she is rudderless in the turbulent seas of transformation; the acquisition of a rudder may not calm these seas, but, at minimum, it provides direction. After all, quixotic goals such as Universal Bibliographic Control may never be achieved, or even considered desirable; yet, they provide discussions with an analytical framework and provoke spirited debate.

The concept of intellectual craft was a key concern of the pioneering American sociologist C. Wright Mills. In an appendix to his treatise on the nature of the social sciences The Sociological Imagination (1959) and in his examination of the American middle classes White Collar (1956), Mills outlines what he sees as the characteristics of intellectual craftsmanship. By using the concept of craft, Mills describes the relationship of the individual intellectual craftsperson to the specific task of a carrying out a particular social research project and its relationship to a larger sense of social science and history. Just as the craftsperson is aware of the context in which a particular task is performed in relation to the whole finished product, as a social scientist, Mills was concerned with the craft of elucidating the relationship between the biography of the individual and the issues of a larger society. Richard Sennett's The Craftsman (2008) marks another touchstone in a contemporary articulation of the ideal of craft. Sennett argues that specific forms of "bodily practices" that engage both "the head and the hands" are key aspects of craftwork that has been transformed not only by industrialization but by the Post-Fordist forms of work organization that force laborers to constantly retrain and adapt, thereby disrupting the narrative arc of numerous work lives. Sennett's conception of craft is meant to serve as a corrective to Hannah Arendt's system in The Human Condition (1958). Arendt views labor and work as base animalistic exertions of the body needed to maintain survival and transform nature, and she places these types of activities at the bottom of a hierarchical system that she developed to analyze human action in the world. For Arendt, action, or participation through acting and speaking in the public sphere, is the highest goal of human development. Sennett contends that the ability to creatively apply learned intellectual skill through bodily practice not only brings satisfaction and pride to a job well done, but also provides laborers with a narrative framework to situate themselves within the social 
world in a way that is rare in the turbulent and competitive world of Post-Fordist capitalism; a world in which market forces demand that the laborer continually retrain and adapt to short-term and precarious forms of employment.

Mills's and Sennett's conceptions of intellectual craft can be applied to the practice of librarianship and classification in a robust articulation of information organization grounded in intellectual craft. Firstly, a librarianship driven by an ideal of intellectual craft involves an engagement in the process of material collection, dissemination, and maintenance. Intellectual craftspersons working in a library would have knowledge about incoming material and have a general sense of the materials contained within the collection. This would necessitate their participation in the development of the collection's content and time to reassess the use of that collection. This provides the librarian with a solid understanding of what is contained within the collection, and its relationship to the broader world of information. It is through this process that the individual's relationship to the collection becomes less abstract. In a sense, his or her head and hands become "dirty" through an engagement with the material. Just as a craftsperson creates the arm of a chair with an understanding of that arm's relationship to the rest of the chair, the classifier as an intellectual craftsperson develops the collection's content with an idea of its relationship to the larger social world.

Secondly, the classifier would have autonomy in the practice of learned skill, knowledge, and expertise. Librarianship is a craft that is not learned intuitively, but through study and an engagement in the philosophy (or philosophies) of the craft. In the 20th century, this has taken the form of graduate education. Whatever form it would take, this would involve a study of, and a reflection upon, the history of the preservation and arrangement of information, and an examination of the ways that information is made accessible to social subjects. After having spent time developing these skills, classifiers would then be able to apply them in their day-to-day activities. The cataloger, having spent years perfecting his or her craft, would be able to reflect upon the ways that users would search for a particular item. The cataloger would then be able to apply that understanding to the task at hand, practicing his or her craft autonomously, and using his or her judgment. Through this process, the cataloger will continue to develop this intellectual understanding of the craft through practice and further reflect upon it.
Finally, since an information collection is a social institution constituted of various laborers, the establishment of a communicative, participatory structure that would facilitate the exchange of concepts and acquired skills between workers is essential. Ideally, the craftsperson freely shares expertise and experience with others in order to develop a collective understanding of the entirety of the craft. In this scenario, the specialized skills and knowledge of laborers are freely shared because status is not determined by specialization. The sharing of knowledge and skill becomes a satisfying, productive exchange between communicative equals. It is in this manner that specialization is related to the development of craft. It is not the result of an external imposition; it develops organically through the interplay of individual experience and knowledge. In this manner, the specialization of the individual develops in a way that allows one to comprehend, manage, and conceptualize the whole while working on a specific aspect of that entity.

\subsection{Beyond craft romanticization}

Much of what is currently considered craftwork occurs within the realm of leisure. In the U.S., many hobbyists spend a great amount of time, labor power, and money doing things such as building model trains, knitting sweaters, or working on their old automobiles. Although it would be far less expensive to, say, purchase a sweater at Walmart, a significant number of people spend an enormous amount of free time and effort knitting a sweater anyway (although this contemporary craft activity is a miniscule part of the U.S. economy). Arguably, one of the greatest achievements of the social democratic welfare state of the 20 th century was that it democratized leisure. The labor slogan from the late 19th century, "eight hours for work, eight hours for sleep, and eight hours for what we will," exemplifies this spirit. By reducing the time spent in the wage relation, the working class could then do other things. The rise of the mass entertainment culture in the early 20th century U.S. that thinkers such as Horkheimer, Adorno and Noerr (2002) excoriated helped to occupy this newly found time outside of waged labor. Although many were excluded from much of this postwar bounty of leisure (e.g., African-Americans, women), its sphere was extended considerably, and leisurely "arts and crafts" activities and materials were made more available. In the 1960s, the affluent postwar consumer culture was criticized for lacking deeper meaning and authenticity as much as it was for providing material affluence; 
however, the fact that this leisure sphere emerged for many was a considerable development.

In the U.S., a populist attraction to more localized forms of market relations has proven to be an attractive alternative to an impersonal consumer culture for both the political left and the right. The popularity of Matthew Crawford's Shop Class as Soul Craft: An Inquiry into the Value of Work (2009) exemplifies this kind of populist celebration of craftwork as an alternative to a mass consumer culture. For Crawford, the application of "the hands" to material through a bodily practice breaks through the abstractions of PostFordist forms of production and gives the laborer a clear measure of "excellence" in the application of his or her labor power. In other words, when working as an electrician, the success of the project is measured instrumentally (e.g., the lights turn on) whereas office work is highly abstract and not subject to the same clear measures of excellence or accomplishment. Crawford ends with no broad political or social program; instead, he wishes to persuade his readers that craft has a value that many college-educated people have neglected. Crawford's analysis is of limited use when constructing the idea of classification as an intellectual craft. In classification, the measurement of success or failure is far more abstract than in traditional handcrafts, and Crawford evinces little interest in developing an understanding of specific craft activities within the context of a larger social whole. In order to move beyond craft romanticization, we must examine how the craft impulse in classification manifests itself.

\subsection{User-generated classification}

The rise of Web 2.0 and user-generated classification systems, such as folksonomies, poses unique ethical questions about the practice of classification craftwork. On the one hand, that so many users are willing to generate content and intellectual material for free can be viewed as a direct challenge to craft as practiced by information professionals. For example, instead of using a controlled vocabulary and a classification systems devised by compensated professionals acting in a broadly defined public interest, the participatory classifiers freely donate their labor to add value to these systems. On the other hand, that so many users willingly contribute their leisure time, collective experience, and expertise to improve access to items through the act of classification is a potential expression of intellectual craftwork in that these users create for the simple purpose of improving the end result.
This situation poses complicated ethical questions for advocates of librarianship as an intellectual craft.

The development of large libraries in the 19th and 20 th centuries was the result of specific technologies (e.g., mass printing, microfilm) and decisions about how to best organize this material within a specific social, economic, and cultural context. As Clay Shirky (2005) points out in Ontology is Overrated, library classification systems were designed to best utilize the "number of books on the shelf." Shirky finds that the Web entails a fundamental transformation in how things are categorized, because, through the application of new search technologies, the enormous amount of classified material allows even the worst amateur schemes to become useful. Shirky (2005) finds that, "combining myriad amateur classifications over time, they (amateur classification schemes) will come to be more valuable than professional categorization schemes, particularly with regards to robustness and cost of creation.” In Shirky, we find the image of the hobbyist donating his or her leisure time to engage in the craft of classification in way that threatens to make the professional classifier and librarian a relic of a bygone era.

Participatory classification systems call upon the ideal of craft. User-generated classification schemes thrive through the application of labor-power frequently provided in the realm of leisure and a simple desire to add use value to the item being classified. The user-generated classifier is motivated to improve the content of the item and can use instrumental criteria about the end result (e.g., can more people access this great picture of Mt. Marcy I found on Flickr?). Moreover, these classifiers may engage in many of the elements of intellectual craft: they may examine the broader world of information, they may apply this knowledge autonomously, and they may communicate freely with others interested in the same topic. As Shirky contends, even the worst and least useful usergenerated classification schemes add value to the item and thus contribute to the general knowledge. When hobbyist craftworkers add classification content to an online space, they add value that can be used in a multitude of ways, even items and spaces that strive to be non-commercial alternatives create potential value in that they add to a pool of general knowledge that can be widely used (e.g., to classify information for use in the office) in ways which may include the extraction of surplus value when that knowledge and labor is eventually converted into a commodity.

Karl Marx's concept of surplus value is a key tool in examining the dynamics of how value is created in this 
process. At its most simple, in classic industrial manufacturing, Marxian surplus value is created for the owner of the productive apparatus when the laborer creates value for capitalists beyond their expenses (e.g., wages, machinery) in exchange for wages. In the Grundrisse (1971), Marx predicts that "knowledge and technological expertise objectified in machines combined with the 'general intellect'" (Peterson 2008, 3) will produce a situation in which value is no longer produced solely through the use of labor in manufacturing, and commodities will become further untethered to the specific forms of labor required to produce them, thereby generalizing these productive forces throughout society. This creates a problem for the capitalist in that he or she needs to continually create surplus value in the production of specific commodities in order to generate profit, eventually creating a crisis due to a falling rate of profit that will spell capitalism's demise. The precise nature of Marx's analysis is debated in a voluminous secondary literature, but the variety of capitalisms that developed in the 20th century (e.g., social democracy, neolibralism) complicate Marx's teleology greatly. A strain of theory emerging out of the Italian Autonomia post-Marxist movement in the 1960s emphasizes this reading of the Grundrisse as a key to understanding the ability of capitalism to "deterritorialize" this production of surplus value through adding to the general knowledge (Peterson, 2008). The idea that surplus value is generalized and created outside of the wage relation provides an important lens through which to analyze craft in user-generated classification.

The advocate of an ethical intellectual craft in librarianship and classification is presented with a dilemma: to encourage the production of user-generated classification not only undermines the application of learned professional expertise, it is also built upon uncompensated labor. Additionally, user-generated classification removes the organization of information from institutions acting in a broadly defined public interest and places it into a far more nebulous market relationship. However, what classifier or librarian does not understand the compulsion to apply their understanding of a subject matter of their choosing and consider various ways of approaching the classification of items to improve their accessibility? The philosophical foundation of the modern profession involves a deep engagement in these issues. It should also be noted that librarianship as practiced in the 20th century did not always exhibit components of intellectual craft. For example, shelf reading may well have contributed to the individual's knowledge of the whole information collection, but the work is very monotonous. If a scanner can generate an instant snapshot of all of the books on that shelf, why would anyone argue for the continued practice of shelf reading? To limit these discussions to specific practices within librarianship is insufficient; the advocate of intellectual craft must confront the larger social world. If one is to pose the question "How can the practice of librarianship as an intellectual craft be promoted?" then difficult questions about the nature of work in the Post-Fordist US must also be posed.

\subsection{Intellectual craft and political economy of neoliberalism}

Neoliberal discourse has created imperatives to continually "innovate," "adapt," and "change" that can easily become untethered to librarianship's historic mission and philosophy and to any examination of the effects such changes might have on the practice of the craft. John Buschman (2003) examines a "new public philosophy" embodied in a neoliberal political project that seeks to dramatically diminish the role of public institutions in favor of private institutions engaging in competitive exchange in an idealized "free market." Neoliberal ideologies interpret all human interactions as embodied in a competitive market exchange, and they advocate for the privatization of public institutions due to the belief that competitive market relations always lead to better and more efficient results, and that free markets are inherently the best arbiter of value (Harvey, 2005). Within the context of such discourse, advocating intellectual craft in professional practice runs afoul of arguments about the most narrowly efficient modes of organization. As Tony Judt states in his 2009 polemic "What is Living and What is Dead in Social Democracy," "This propensity to avoid moral considerations, to restrict ourselves to issues of profit and loss-economic questions in the narrowest sense-is not an instinctive human condition. It is an acquired taste." $(2009,86)$ The ethical questions posed by work itself are profound, enduring, and, as Kathi Weeks (2011) claims, underexamined in contemporary political theory.

At their least craft-like, classification and library work can resemble assembly line industrial manufacturing in the production of commodities in which the labor sociologist Harry Braverman found "the labor process is divorced, so far as possible, from special knowledge and reduced to simple labor" $(1975,82)$. This process is exemplified in the Fordist assembly line in which every task is reduced to its most simple 
and efficient component. As the specialized knowledge and training needed to manage and assign access points to information is outsourced, the ability of librarians and classifiers to create access points that are more reflective of localized knowledge is diminished. The very idea of craft is diminished in classification, and the concrete involvement with the information that the classifier uses on a day-to-day basis is lessened. In a Post-Fordist twist, this trend recasts the public service librarians as "customer service agents": laborers with no special knowledge, no solid understanding of how the information that they use has been created, and only a fleeting understanding of their own library and its place in the larger world of information.

Although Marxian concepts such as surplus value are analytically useful, they fail to provide an ethical account of these issues. Within the context of a library or information center, the principles guiding intellectual craft could be easily evaluated by the criteria established earlier in this paper. No library is an island unto itself, and the ideals of intellectual craft clearly contradict workplace organization chiefly arranged around an ethic of absolute market efficiency. We have seen how user-generated content is created by harnessing the craft impulse that does not think of efficiency or the creation of economic value, but simply wants to add to a social body of knowledge. For professional classifiers, it would be all too easy to condemn the hobbyist as a threat to their practice of intellectual craft, but such a conflict poses the wrong ethical questions. Instead, the defense of information organization in the public interest and a generalized reduction of working time are the two best, admittedly utopian, tactics for pursuing an agenda of librarianship as an intellectual craft.

On the one hand, the idea that sometimes the most efficient form of workplace organization is not always the most beneficial to society is important to affirm. Libraries embody an egalitarian idea of "information for all," and the work of trained, compensated professionals can create dynamic information systems in which a participatory democracy in classification is supplemented by professional classifiers that add value to systems that may not be apparent to most users in the short term. Libraries are part of a bigger society, and they must play a role in asserting that funding public institutions (like libraries) is a key component of a good, just, and free society, and that simply relying on a mythical free market will never guarantee ideally organized systems of information. Of course, public institutions will never be free of problems, but they fill crucial gaps in the spaces which markets fail to address.

Kathi Weeks' (2011) recent examination of the work ethic bears mentioning because she advocates for what, within the midst of the worst recession since the Great Depression, would seem to be a counterintuitive and utopian argument: a reduction in the amount of time spent in waged labor coupled with a guaranteed income. To guarantee more time away from the wage relation for more people would increase the opportunities for participating in new hobbyist forms of craft or simply more time with friends and family. The idea that leisure should be viewed as a right contrasts with how the work ethic is discussed in the U.S., but as we have seen in our discussion of user-generated content, the act of adding to the general knowledge and producing value can no longer be easily separated from the wage relation. As fewer people are driven by necessity to work more hours in occupations in which their sense of craft is diminished they may, or may not, be willing to add their labor and knowledge to the general pool of knowledge. For information professionals to discourage this craftwork, or to place themselves in opposition to it, is neither ethical nor realistic.

\subsection{Conclusion}

The ideal of intellectual craft in librarianship and classification is decreased when the individual librarians' understanding of the world of information is diminished and their ability to autonomously practice their craft is encroached upon, and when individual classifiers are prevented from communicatively sharing their skills. Therefore, the discursive environment of neoliberalism demonstrates that these changes have little to do with technology as such, but everything to do with commonsense notions of technological change in the societies within which these institutions exist. Therefore to advocate for a normative ideal of intellectual craft in libraries necessitates an engagement in the broader world of work, economics, and public institutions. As social and economic forces continually transform the ways that libraries are perceived, workplace activity in the libraries of the future will be tied to the workplace activity of the population in general. In this paper, I have argued that, to encourage an ideal of intellectual craft in classification, the importance of public institutions and the expansion of leisure are keys to extending this ideal as a professional ethical practice. The dramatic nature of these technological and economic transformations 
elude easy answers. The idea of intellectual craft proposed in this paper provides information professionals with an idealized standard with which to evaluate work activity; hopefully, additional ethical accounts of these transformations will emerge as these transformative social forces continue reshape professional practice.

\section{References}

Arendt, Hannah. 1958. The buman condition. Charles R. Walgreen Foundation lectures. Chicago: University of Chicago Press.

Braverman, Harry. 1975. Labor and monopoly capital: the degradation of work in the twentieth century. New York: Monthly Review Press.

Buschman, John. 2003. Dismantling the public sphere: situating and sustaining librarianship in the age of the new public philosophy. Westport, Conn.: Libraries Unlimited.

Crawford, Matthew B. 2009. Shop class as soulcraft: an inquiry into the value of work. New York: Penguin Press.

Harvey, David. 2005. A brief history of neoliberalism. Oxford: Oxford University Press.

Horkheimer, Max, Adorno, Theodor W., and Noerr, Gunzelinn Schmid. 2002. Dialectic of enlightenment: philosophical fragments. Stanford, Calif.: Stanford Univ. Pr.

Judt, Tony. 2009. What is living and what is dead in social democracy? New York review of books 56n20: 86-97.

Marx, Karl. 1971. The Grundrisse. New York: Harper \& Row.

Mills, Charles Wright. 1951. White collar: the American middle classes. New York: Oxford University Press.

Mills, Charles Wright. 1959. The sociological imagination. New York: Oxford University Press.

Petersen, Søren Mørk. 2008. Loser generated content: from participation to exploitation. First Monday 13n3. Available http://www.uic.edu/htbin/cgiwrap/ bin/ojs/index.php/fm/article/view/2141/1948.

Polanyi, Karl. 2001. The great transformation: the political and economic origins of our time. Boston, Mass.: Beacon Press.

Sennett, Richard. 2008. The craftsman. New Haven, Conn.: Yale University Press.

Shirky, Clay. 2005. Ontology is overrated: categories, links, and tabs. Available http://www.shirky.com/ writings/ontology_overrated.html.

Weeks, Kathi. 2011. The problem with work: feminism, Marxism, antiwork politics, and postwork imaginaries. Durham, NC: Duke University Press. 